\title{
Spills of Acids and Bases
}

\author{
Felix Gsell
}

\begin{abstract}
Due to their hazardous characteristics acids and bases present an intrinsic risk in the event of spillage. To prevent injuries from chemical contamination, HazMat unit personnel use protective suits and proper decontamination procedures. Nitrous acid is especially insidious since it causes severe burns with wounds that take a long time to heal. In addition it produces hydrogen and nitrous oxide gases by redox reactions with metals. Risk assessment for a production site and case studies of incidents are presented.
\end{abstract}

Keywords: Decontamination · Nitration · Nitrous acid · Protective equipment $\cdot$ Risk assessment

\section{Introduction}

EMS-Dottikon AG is a chemical production site with about 400 employees and 200 plants and buildings. The company provides fine chemicals for the life sciences and plastics industries. Since the roots of EMS-Dottikon AG go back to the production of explosives (former name Schweizerische Sprengstoff Fabrik) nitration is still a core business of the company. These chemical reactions require large amounts of acids and bases such as nitrous acid, sulfuric acid, hydrochloric acid, acetic acid, acetic anhydride, propionic acid, phosphorous oxychloride, thionyl chloride, and caustic soda. In these processes, the used acids with by-products are purified to high grade 98\% sulfuric acid and 99\% nitrous acid. The origin of these used acids are absorption units and waste products of nitration and oxidation reactions. Handling acids is therefore daily business in the 90year history of EMS-Dottikon AG.

The private fire brigade was founded in 1938. In the years since then, the fire brigade has evolved from relatively modest beginnings to a well-equipped HazMat base for part of canton Aargau. About 100 volunteers form the crew. This includes an analytical team and a paramedic team.

\section{Hazard Potential of Acids and Bases}

\section{a) Corrosive Effect on Humans}

The main danger is inhalation of acid vapors. These vapors cause pulmonary edema (alveoli become damaged and the lungs fill with water) or severe damage to the destroy respiratory tract. Reversible or even irreversible damage can hinder respiration for life.

The second danger is the corrosive effect on eyes, mucous membranes and skin (Fig. 1). The worse effects are based on protein degradation paired with exothermic generation of heat. The extent of the damage is dependent on concentration, potency, temperature, and time of impact. The exothermic properties of protein degradation explain why corrosion damage often also results in burns. By-products can enter blood vessels and result in a toxification of the patient.

\section{b) Corrosive Effect on Materials}

Selection of appropriate containers and materials is crucial for safe handling of acids and bases. There is no cheap, all-purpose material for acids and bases. Only skilled corrosion specialists can provide technical advice. For example iron is suitable for highly diluted or concentrated sulfuric acid. But in the range between $20 \%$ and $80 \%$ it is attacked quickly. As in chemical reactions, higher temperatures speed up corrosion. The oxidation process is often paired with hydrogen and toxic gas production.

\section{c) Basic Principles When Handling Acids and Bases}

To prevent aggravation of the situation some rules must be applied strictly.

- Do not splash water into acids or bases, since

- spilled material spreads;

- the heat of hydration can cause local spots with water above boiling

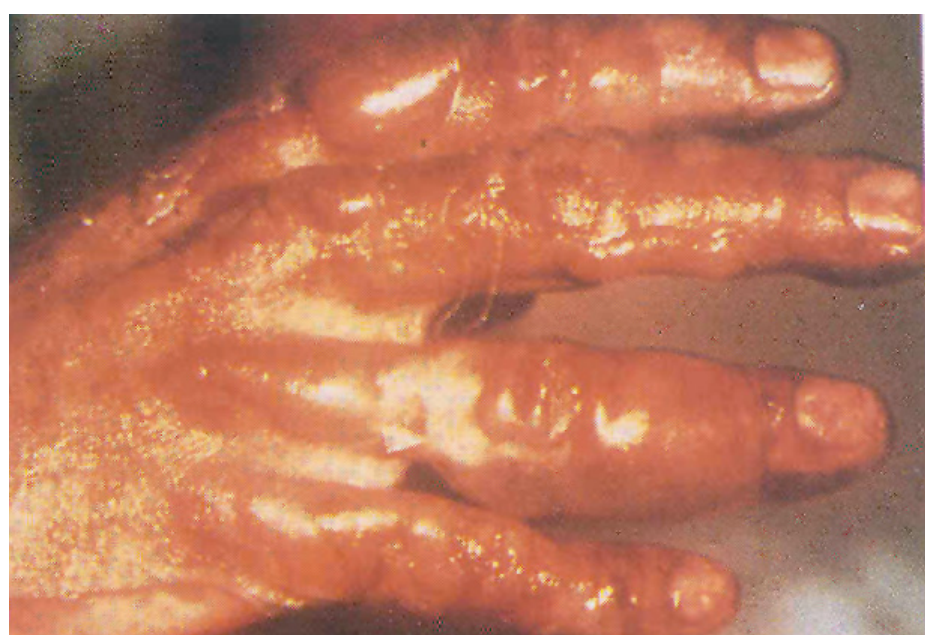

Fig. 1. Severe skin corrosion on a contaminated hand 
point resulting in the eruption of acid drops;

- the release of enormous quantities of

$\mathrm{HCl}$ occurs with acid chlorides.

- Physical isolation is preferred to dilution or neutralization.

- No organic binder materials for oxidizing acids due to the fire hazard.

- Neutralization should only be carried out with decontamination.

- Provide fire protection and ventilate basements as counter measure to possible hydrogen production.

- Collect spilled liquids to avoid uncontrolled run-off.

- Adjust to $\mathrm{pH}$ range 5 to 9 before disposal to sewers.

- Inform the responsible authority and advise waste water treatment plant manager, who will have an emergency plan.

\section{Risk Assessment for Handling of Acids and Bases}

Fundamentally EMS-Dottikon AG ensures that incidents do not have consequences in residential areas. Therefore handling of chemicals is limited. The fire chief determines the acceptable quantities based on the toxic effects of the chemicals. Safety of internal transports has to be secured by proper transportation and strictly executed packaging guidelines.

\section{Case 1}

Hydrogen chloride in pressurized containers is used in a plant. The distance to the next residential area is about $600 \mathrm{~m}$. With a simple dispersion model, 'Modell für Effekte mit toxischen Gasen (MET)' [1], the plume extension area is determined based on worst case scenarios. In this case about $40 \%$ of the material is suddenly released by spontaneous evaporation (flash fraction). Weather conditions are less important with spontaneous evaporation. A guide value $<500 \mathrm{~kg} \mathrm{HCl}$ per container was determined. The intervention of the fire brigade provides additional safety.

\section{Case 2}

In a tank farm 30 to of vitriolic nitrous acid should be stored. With aqueous liquids, spontaneous evaporation is not relevant. Therefore estimation of pool size is an indicator for evaporation. Normally a surface area $<200 \mathrm{~m}^{2}$ is recommended. Evaporation is favored by warm temperatures without turbulence. For the risk assessment a warm summer night is assumed. Again intervention of fire brigade is not taken into account. With nitrous acid it is important that water is only used to knock down vapors and does not come into contact with the acid.

\section{Case 3}

When limitation of surface areas or quantities cannot provide adequate protection, chemicals have to be handled in containment. Escaped material is vented and neutralized in a scrubber or adsorbed. As neutralization agents, chemicals such as suitable acids, bases or other chemicals such as thiosulfate for bromine or ammonia solution for dimethylsulfate are used.

\section{Protective Equipment}

Staff are protected by working in a closed operation mode or by venting vapors at the source. Despite these precautions, incidents can be triggered by mishap, technical failure or human error. Therefore personal protective equipment should be worn in the plant. In the intervention mode of the fire brigade, contamination of HazMat technicians is likely. In our fire brigade we have defined different protection levels.

\section{Rescue Mission}

An immediate rescue is vital for the patient. Therefore a rescue mission is performed in fire-protective clothing, breathing apparatus, gloves and boots. This equipment enables fast intervention even in very high vapor concentrations. The officer-incharge is responsible for adequate fire protection (at least a powder extinguisher) and a proper decontamination of patients and fire services personnel and material.

\section{Intervention Against Spills}

The officer-in-charge or the scientific officer should define the appropriate protection level. Light PVC suits with boots and breathing apparatus or gas-tight protective suits are possible.

\section{First Aid Material}

Principally decontamination is performed with water. Speed is essential (see article of F. Geissmann in this special issue [3]). Since we have especially good experience with Previn ${ }^{\circledR}$ (www.prevor.com) this option is described here. Previn is an amphoteric substance and therefore suitable to bind acids, bases and other chemicals. With the adsorption of chemicals their hazardous effect is contained. Two things are important:

1) Previn has to be used immediately.

2) Corrosion lesions are often also burns. Therefore, after removal of chemicals, a treatment similar to burn patients should follow.

To demonstrate the excellent effect of Previn, experience gained from three nitrous acid contaminations is presented.

\section{Case Study 1}

A new product was synthesized in a pilot plant by means of a nitration reaction. The reaction mixture, nitrous acid, sulfuric acid and products, was transferred with a membrane pump into a second vessel with ice. Collectively we observed events in the reactor and through the inspection glass of the transfer pipe. Suddenly color in the inspection glass turned from red/brown to black. A decomposition reaction had occurred. The pressure increase resulted in the inspection glass bursting. Unfortunately a chemist was hit on the leg by the reaction mixture. We started immediately with decontamination with plenty of water. The effect was disappointing. The accident resulted in an absence from work for more than one month since the skin lesion healed badly. This painful experience was the motivation to look for an alternative decontamination procedure. The reason for this incident was a broken pump membrane. As a consequence lubricant entered the reaction mixture and started the decomposition process.

\section{Case Study 2}

An employee found that a feed pump of an acid recycling plant was not working. On the pressure side the pipe was plugged. He started to disassemble the pipe without releasing the pressure. The employee received acid splashes in his face. Instinctively he went under the shower. About 3 min later paramedics treated the corrosion with Previn. The typical yellow, ulcerating wound was not observed (Fig. 2). The clinical picture and statements of the victim indicated a burn. He was absent from work for eight days.

\section{Case Study 3}

An employee pumped warm $99 \%$ nitrous acid with a dosing pump. A valve in wrong position led to a rupture of a pipe connection and nitrous acid splashed the head of the employee. Helmet and protective shield prevented the worst. Some acid entered an ear. The wound was immediately decontaminated with Previn and then treated as a burn. The employee was only absent from work for two days.

\section{Intervention Concept for Incidents with Acids and Bases}

The procedure is always more or less the same.

\section{Urgent Measures}

- Prevent entry of persons or cars to the scene.

- Check if sufficient fire services personnel are available. If not, call for more fire fighters.

- Remove all ignition sources. 


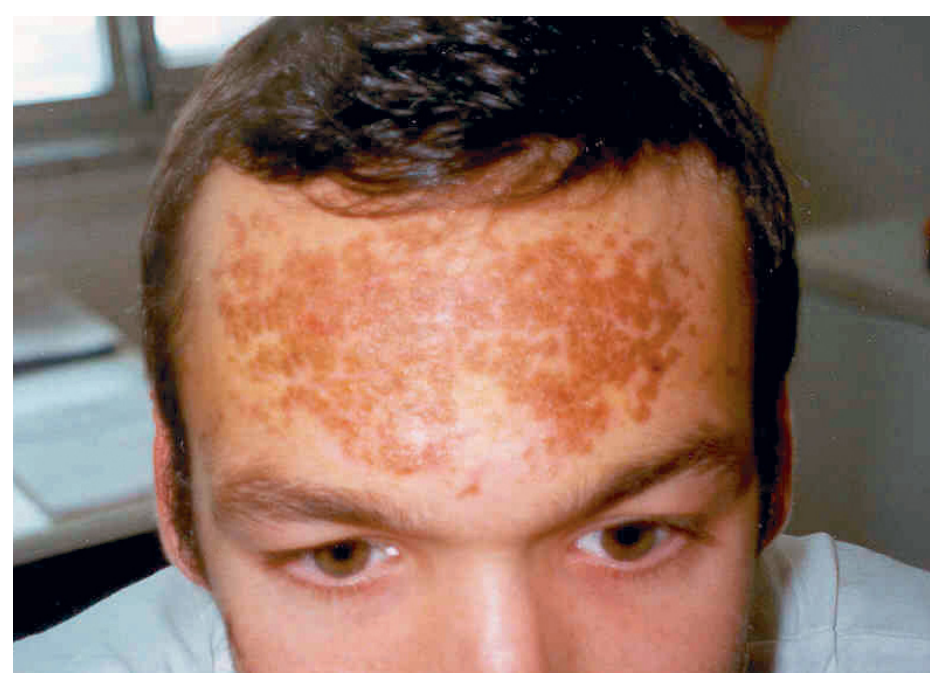

Fig. 2. Typical wound caused by nitrous acid corrosion. The healing process is well advanced.

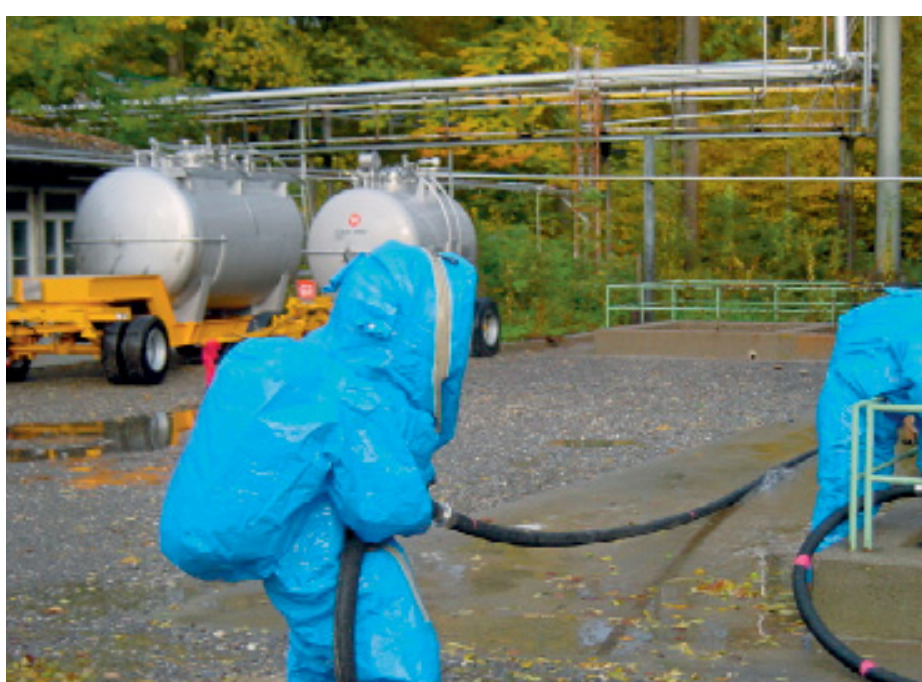

Fig. 3. HazMat technicians in gas-tight protective suits install long suction pipe (left) and short pressure pipe (right) for a pumped transfer of chemicals with an ELRO pump

\section{Rescue People and Animals}

- Rescue patients with protective equipment.

- Start immediately with first aid and decontamination.

- Check for missing people. If there are any, start manhunt.

\section{Prevent Propagation}

- Cordon off the scene.

- Isolate spilled material.

- Improve fire protection if necessary.

- Prevent entry of chemicals in sewer system, water bodies or soil.

- Knock down toxic vapors.

- Seal the leak.

\section{Salvage Measures}

- Do everything to ensure a safe situation and prevent collateral damage.

\section{Spills With Corrosive Chemicals}

\section{Case Study 1 - Nitrous Acid 60\%}

Nitrous acid 60\% was delivered in 6001 plastic containers to a galvanization factory. The driver parked his truck in a street with an upwards gradient. With a hand forklift he transported the pallet with the container. Due to the downward slope the shipment started to move and could not be stopped. The container fell on the floor and cracked. Part of the acid leaked onto a parked car and then on the tarred forecourt. The production of nitrous oxide began immediately. Before sinks could be closed, about 501 of the acid ran into the sewer system. The entry to the scene was blocked and the local fire brigade called for the HazMat unit.
Actions of Local Fire Brigade:

- Ensure that no persons are involved.

- Notification of the waste water treatment plant.

- Tightening the sink by fire services personnel protected with breathing apparatus.

- Cordon off the scene and installation of a provisional decontamination place

- Traffic management.

Actions of HazMat Unit:

- Ensure that in fact no persons are involved.

- Secure remaining nitrous acid in the container.

- Disperse non-organic binding material.

- Dispose of binding material in fiber drums.

- Neutralization of the scene with sodium bicarbonate.

- Rinse the scene with plenty of water.

- Check pH-value in the sewer near wastewater treatment plant.

- Check equipment with $\mathrm{pH}$ indicator strips and decontaminate if necessary.

\section{Case Study 2 - Nitrous Acid and Ex- plosives}

Explosives are produced by dosing reactant to vitriolic nitrous acid. By-products must be destroyed by gentle oxidation. This reaction has to be well controlled otherwise a violent decomposition starts.

Decomposition can result in a detonation of the explosive. Reactors are equipped with an emergency vessel for quenching when decomposition starts. In 2002 this emergency measure had to be used in our company. With quenching, considerable amounts of nitrous oxide were produced. The toxic gases were washed out partly by the deluge system and partly by water spray from the monitors. The analytical team took samples in the surroundings to check for danger to the local population. Within residential areas at no time was the MAK limit threshold exceeded. Results and measuring tubes were handed over to the police. A big challenge were about $100 \mathrm{~kg}$ explosive pellets remaining together with $50 \%$ nitrous acid in the emergency vessel. The Officerin-charge, plant chemist and production manager decided to pump the suspension with a peristaltic pump (ELRO pump). This pump produces practically no friction. To separate acid and pellets, the suspension was transferred to an open suction filter. HazMat technicians involved wore full protective suits. To minimize the risk only three people were in the endangered area. The combination of a long suction pipe and a short pressure pipe with the ELRO pump was once more a success (Fig. 3).

Received: November 11, 2003

[1] 'Technischer Behelf für den Schutz bei CEreignissen, MET (Modell für Effekte mit toxischen Gasen)', Zentralstelle für Gesamtverteidigung, EDMZ Bern, 1991, Nr. 581.031d (out of stock): today it is integrated in [2].

[2] H.D. Nüssler, 'Gefahrengut Ersteinsatz', Storck Verlag, Hamburg, 2000, ISBN 3923190-33-6.

[3] F. Geissmann, Chimia 2004, 58, 33. 